\title{
CLIMATE RISING AND FALLING STATE OF HYDROSPHERIC OXYGEN LEVEL: A GRIM GLOBAL CONCERN
}

\author{
Mohammad Afsar Alam ${ }^{1 *}$ and Mumtaz Alam ${ }^{1}$ \\ ${ }^{1}{ }^{2}$ Department of Social Science, School of Arts and Humanities \\ Fiji National University, Fiji
}

Received on: 21.06.2021

Revised on: 29.06 .2021
Accepted on: 30.06 .2021

\author{
Keywords \\ Climate rising, Lakes, Oceans, \\ Oxygen Loss, Seas
}

\begin{abstract}
Though humans' basic needs are prioritized first, health and environment quality are equally important. Environmental issues are based on a variety of factors. One of these is the rising temperature and consequent decrease in oxygen levels in water bodies such as lakes, oceans, and seas. The right amount of oxygen is essential for life on Earth because it serves as a lifeline for living organisms; it could jeopardize marine ecosystems, shifting habitat conditions, human health, and the environment as a whole. The data for this study were primarily gathered from secondary sources such as books, government offices, research articles, and websites published at various times. According to research, the primary cause of marine oxygen loss is human-caused global warming. Human beings also play a role in coastal regions by depositing wastes in the water bodies, moreover it is difficult to avoid this completely. Most significant drops in oxygen levels have been noticed in the equator and the Arctic Ocean. The spatial distribution and pattern of low or no oxygen across the globe is the focus of this review article. It also goes over the reasons for unequal oxygen loss in different parts of the world.
\end{abstract}

\section{Introduction}

According to the most recent and comprehensive research of Oxygen Changes in the World's Oceans, total global oxygen concentration has decreased by $2 \%$ on an average between 1960 and 2010. (Laffoley and Baxter, 2019).Climate change is considered to be a key cause to this "deoxygenation," since it affects the quantity of oxygen that seawater can contain as well as the circulation patterns that deliver oxygen-rich water to deeper oceans. There are pockets of little or no oxygen all around the planet, including sections of the tropical oceans off the coasts of California, Peru, and Namibia, as well as the subterranean waters of the Arabian Sea. Most marine life will perish since the oxygen levels in these places are so low. Nitrous oxide $\left(\mathrm{N}_{2} \mathrm{O}\right)$, a strong greenhouse gas, can be released in low oxygen zones (Schmidtko S, Stramma L, Visbeck M., 2017). This paper aims to demonstrate how the rising temperature of the climate affects the level of oxygen in the hydrosphere.
The world is now more than $1^{\circ} \mathrm{C}$ warmer than before industrialization, and it is on track to be 3 degrees warmer in the near future. Compared to natural processes that affect climates, such as solar fluctuation and volcanic eruptions, human actions, primarily the burning of fossil fuels and deforestation, have contributed to climate change over the last 50 years.

According to NASA and the National Oceanic and Atmospheric Administration's alarming new analysis, the amount of heat trapped by the Earth has doubled in just 15 years. According to researchers, it's a massive amount of energy that's already having far-reaching effects.

According to NASA scientist Norman Loeb, the planet is absorbing too much energy, which will result in higher temperatures and more melting of snow and sea ice, as well as a rise in sea level. Scientists discovered that the Earth is 
gaining more energy than it should, causing the planet to heat up even more. Around $90 \%$ of the excess energy generated by this imbalance ends up in the ocean. Warming ocean temperatures also cause acidification and oxygen depletion, which hurts fish and other marine biodiversity (Loeb $\mathrm{N}$, Lyman et. al., 2012).

According to the researchers, human-induced greenhouse gas emissions are certainly a part of the cause of this energy imbalance. As the global temperature rises, the amount of water vapour in the atmosphere rises and raises the temperature even more. Melting snowpack and sea ice, which act as natural solar reflectors, are also diminishing due to climate change (Rachel Ramirez, June 18, 2021, CNN). Norman Loeb opines that the rate that we're seeing this energy imbalance should subside in the coming decades, otherwise, more alarming climate changes will be witnessed.

\section{Objectives of the study}

One of the goals of this research is to gain a better understanding of how rising temperatures affect the amount of oxygen in the hydrosphere and to examine how oxygen is lost in the oceans, seas, and lakes. In addition, the impact of oxygen loss on marine ecology will also be assessed. Furthermore, mitigation measures are taken into account in order to predict future trends in oxygen levels.

\section{Methodology}

The research was carried out using secondary data gathered from a variety of sources i.e., published books as well as unpublished soft copies obtained via the internet and software. Also, several articles published in various national and international journals for this purpose were consulted.

\section{Background Literature}

It is important for all higher forms of marine life to have access to oxygen, even though it accounts for just approximately 0.6 percent of the total amount of oxygen in the atmosphere. Furthermore, the respiration of organisms uses oxygen on a continual basis virtually everywhere in the water. An average of $2 \%$ decrease in oxygen concentration in the worldwide seas has been observed since 1960, according to the most current and thorough investigation of oxygen variations in global oceans. The amount of deoxygenation varies significantly across the seas, according to the study. The equator and the Arctic have seen the most significant drops in oxygen levels.

Marine oxygen depletion is believed to be mostly driven by human-induced global warming, according to recent studies. Humans also have a role in coastal regions by giving nutrients to the oceans, however it is difficult to distinguish between the many mechanisms at action.

The ocean and its dissolved oxygen concentration are both affected by global warming in a variety of ways. The solubility of oxygen in water is one of the effects of this compound, among others. The amount of gas that can dissolve in warm water is proportional to the amount of gas that can dissolve in cold water. The upper few hundred meters of the ocean's surface, which have only recently come into contact with the atmosphere, have been the primary target of this process up until now. It has been estimated that this phenomenon is responsible for up to $20 \%$ of total marine oxygen loss to date, with around $50 \%$ of that loss occurring in the upper 1,000 meters of the ocean.

Furthermore, worldwide ocean circulation patterns are altered as a result of warming, with the mixing of oxygen-rich surface waters with oxygen-poor deeper water being affected. It also has an impact on the consumption of marine oxygen because it alters the pace at which organisms metabolize and respire, among other things.

Finally, when it comes to nutrient availability and production in the upper ocean, warming has an indirect influence on downward export of organic matter accessible for respiration across the ocean (Oschlies, A. et al., 2018).

\section{Climate Induced Changes}

When academics and other social scientists began researching globalization in the late 1980s and early 1990s, climate change became widely recognized (Alam, 2021). Climate change is one of the most serious environmental threats humanity has ever faced. There is more to it than just hot air and melting ice. It has far-reaching consequences that extend beyond where people live and where food is grown. People with more knowledge are better able to assess the risks posed by climate change and have less perceived ambiguity about it, which influences their pro-environmental behavior (Alam et. al, 2021). During the twentieth century, water temperatures in several lake habitats around the world rose (Austin \& Colman, 2008; Schneider \& Hook, 2010). Deeper water levels in lakes change less frequently than surface waters (Pilla,2021). The ecological health of lakes and reservoirs around the world is still threatened by low dissolved oxygen levels. Additionally, climate-induced changes in lake stratification and mixing constitute an anthropogenic hazard, resulting in reduced deep-water oxygen levels as a result of increased nutrient loads. (Saros, 2012; Savin, 1977). Temperature increase as a result of global warming is the major cause of decreasing oxygen levels in the atmosphere, as warmer water cannot store as much oxygen. Furthermore, as summer temperatures rise, the top layer of lakes becomes hotter and less thicker than the water below, causing plummeting, mixing, and reduced oxygen delivery to the depths. According to scientists, oxygen levels in deep seas have decreased by 19\%, while surface levels have decreased by $5 \%$ (2002, Portner).

Oxygen levels have increased at the surface of some lakes. Warmer temperatures, on the other hand, are more likely to cause algal blooms, which can produce harmful chemicals (Hallegraeff, 2003; Karlson et al. 2021). According to a recent research, the world's lakes are being suffocated by the climate catastrophe. According to experts, climate rising is triggering oxygen levels in lakes to drop, resulting in the 
extinction of species and the jeopardization of drinking water supplies. According to a study, oxygen levels in lakes have decreased three to nine times faster in the last 40 years. Lake Ammersee is one of Germany's climate-vulnerable lakes (Kraemer, et al., 2021; Woolway, 2021).

"All complex life relies on oxygen, and as oxygen levels fall, many different species' habitats are significantly reduced" (Jane et al., 2021). Since 1970, the average animal population has decreased by 84 percent. One of the reasons, in addition to global warming and pollution, is the excessive use of water for farming. Freshwater ecosystems' fish, insects, birds, and mammals have already been severely harmed.

Despite the fact that the majority of the lakes studied were in temperate zones, particularly in Europe and the United States, there were a few records from higher latitudes, closer to the poles, as well as tropical lakes in Africa. The study found that, regardless of location, oxygen levels were decreasing (National Research Council, \& Climate Research Committee, 1996).

Surface water oxygen levels were rising in nearly a fifth of the lakes studied, and nearly all of them were polluted. This is a sign of widespread algal blooms, according to Rose: "We couldn't tell for sure without taxonomic data, but nothing else we know of can explain this pattern.”

Even maintaining the status quo, as global temperatures continue to rise, lowering lake oxygen levels necessitate cleaning up freshwater bodies. According to Rose, a clean-up at Oneida Lake in New York resulted in improved water clarity, which allowed for increased photosynthesis from oxygen-producing algae (Dale et al., 2006).

According to the scientists' best-case scenario, just $10 \%$ of the examined species would be endangered during the next 80 years if the global temperature climbed by $1.5{ }^{\circ} \mathrm{C}$. Researchers determined that if global warming exceeds preindustrial temperatures by $4-5^{\circ} \mathrm{C}$ by 2100,60 percent of the fish species tested will be unable to live in their current habitats $\left(7.2^{\circ} \mathrm{F}\right)$. A study of over 700 freshwater and saltwater fish species examined how changing water temperatures impact water oxygen levels, placing embryos and pregnant fish at risk of being killed or severely injured (Dahlke et al., 2018).

Even under this scenario, the Atlantic Cod, Swordfish, Pacific Salmon, Alaska Pollock, and Pacific Cod that are used to produce frozen fish sticks, which are both economically and environmentally valuable, are still in danger of being depleted. A 10 percent loss in species can have substantial consequences for the entire ecosystem "stem," making it difficult to estimate the consequences of a 10 percent loss in species. Take, for example, the North Sea, where we anticipate that the temperature will have increased to the point that Atlantic Cod would be unable to spawn by the end of the century. Flemming T. Dahlke and colleagues from the
Alfred-Wegener Institute, Helmholtz Centre for Polar and Marine Research, University of Bremen, Germany, explained that because it is such a significant predator, removing it from the system has a significant impact on the ecosystem as a whole as well as all the processes and interactions between species (Dahlke, et al., 2018).

When the temperature rises, fish use more energy and demand more oxygen. The heat, on the other hand, reduces the amount of oxygen available. Embryos, which cannot regulate their oxygen levels, and spawning fish, which require more oxygen to produce progeny, are particularly vulnerable in these conditions.

Dahlke noted that this estimate is conservative because it excludes other climate-related issues that could harm marine life, such as ocean acidification, which could exacerbate the effects on vulnerable species.

"Some tropical fish are already living in zones where their maximum tolerance has been reached, in places where the temperature has reached 40 degrees," Portner says (Prof Hans-Otto Portner, a climatologist of the Alfred-WegenerInstitute in Bremerhaven, Germany) He went on to say, "Humans are pushing the planet's temperature range out of a livable range, and we're losing good habitat as a result. It is worthwhile to contribute to the $1.5{ }^{\circ} \mathrm{C}$ target." (Portner, 2002).

\section{Appropriate Ocean Surveillance}

Ocean oxygen depletion is being widely recognized as a serious danger to marine ecosystems and changing habitat conditions in many regions of the world's oceans, particularly in the Pacific. Increased likelihood of deoxygenation feedbacks on climate, including the generation of strong greenhouse gases such as $\mathrm{N}_{2} \mathrm{O}$ and methane in low-oxygen circumstances is associated with a warmer temperature. As a result, it is important to resolve the disparity between observations and models, which is eventually necessary for trustworthy future forecasts. To overcome these gaps, we propose that more extensive and internationally coordinated ocean observations be conducted. In addition, multidisciplinary process studies are required to better understand the delicate balance between oxygenation and oxygen consumption in the seas which are always changing. Another advantage of improving the models in terms of the ocean oxygen budget is that oxygen is a good parameter for calibrating models that compute the ocean's $\mathrm{CO}_{2}$ uptake, which is another benefit of improving the models in terms of the ocean oxygen budget. We would also acquire a better knowledge of the carbon cycle as a result of this experiment (Oschlies, A. et al., 2018).

\section{Conclusion}

To avoid the worsening ramifications of climate change, an alternative arrangement is required to maintain the rising and falling state of hydrospheric oxygen levels. Many innovators are introducing technology or business models that produce 
less carbon than current methods, such as leather made from mushrooms instead of animal hide, electric cars instead of fossil fuels, etc. In addition, scholars are looking into new technologies to reabsorb carbon that has already been released into the atmosphere in order to find new ways to combat climate change from a different angle. These methods have many potential benefits, but they also have a lot of challenges right now.

\section{References}

1. Alam, M., History, Historians and Anthropocene, Scholarly Journal of Psychology and Behavioral Sciences, 2021 June, Vol 5, Issue 2. 559-561.

2. Alam, M.A, Alam, M. and Kundra, S., Knowing Climate: Knowledge, Perceptions and Awareness (KPA) among Higher Education Students in Eritrea, Disaster Advances, 2021 Martch, 14 (3) 30-39.

3. Anderson EJ, Stow CA, Gronewold AD, Mason LA, McCormick MJ, Qian SS, Ruberg SA, Beadle K, Constant SA, Hawley N. Seasonal overturn and stratification changes drive deep-water warming in one of Earth's largest lakes. Nature communications. 2021 Mar 16;12(1):1-9.

4. Austin J, Colman S. A century of temperature variability in Lake Superior. Limnology and Oceanography. 2008 Nov; 53(6):2724-30.

5. Dahlke FT, Butzin M, Nahrgang J, Puvanendran V, Mortensen A, Pörtner HO, Storch D. Northern cod species face spawning habitat losses if global warming exceeds 1.5 C. Science advances. 2018 Nov 1;4(11):eaas8821.

6. Dale B, Edwards M, Reid PC. Climate change and harmful algal blooms. In Ecology of harmful algae 2006 (pp. 367-378). Springer, Berlin, Heidelberg.

7. Hallegraeff GM. Harmful algal blooms: a global overview. Manual on harmful marine microalgae. 2003;33:1-22.

8. Jane SF, Hansen GJ, Kraemer BM, Leavitt PR, Mincer JL, North RL, Pilla RM, Stetler JT, Williamson CE, Woolway RI, Arvola L. Widespread deoxygenation of temperate lakes. Nature. 2021 Jun;594(7861):66-70.

9. Karlson B, Andersen P, Arneborg L, Cembella A, Eikrem W, John U, West JJ, Klemm K, Kobos J, Lehtinen S, Lundholm N. Harmful algal blooms and their effects in coastal seas of Northern Europe. Harmful Algae. 2021 Mar 6:101989.

10. Kraemer BM, Pilla RM, Woolway RI, Anneville O, Ban S, Colom-Montero W, Devlin SP, Dokulil MT, Gaiser EE, Hambright KD, Hessen DO. Climate change drives widespread shifts in lake thermal habitat. Nature Climate Change. 2021 Jun 3:1-9.
11. Laffoley D, Baxter JM. Ocean Deoxygenation: Everyone's Problem-Causes, Impacts, Consequences and Solutions. Gland, Switzerland: IUCN; 2019.

12. Loeb N, Lyman JM, Johnson GC, Doelling DR, Wong T, Allan RP, Soden BJ, Stephens GL. Heating of Earth's climate system continues despite lack of surface warming in past decade. Nature Geosci. 2012.

13. National Research Council, Climate Research Committee. Natural climate variability on decade-tocentury time scales. National Academies Press; 1996 Aug 30.

14. Oschlies A, Brandt P, Stramma L, Schmidtko S. Drivers and mechanisms of ocean deoxygenation. Nature Geoscience. 2018 Jul;11(7):467-73.

15. Pilla RM. Lake Vertical Ecosystem Responses to Climate and Environmental Changes: Integrating Comparative Time Series, Modeling, and HighFrequency Approaches (Doctoral dissertation, Miami University).

16. Portner HO. Climate variations and the physiological basis of temperature dependent biogeography: systemic to molecular hierarchy of thermal tolerance in animals. Comparative Biochemistry and Physiology Part A: Molecular \& Integrative Physiology. 2002 Aug 1;132(4):739-61.

17. Rachel Ramirez, The amount of heat the Earth traps has doubled in just 15 years, study shows, June 18, 2021, CNN,https://edition.cnn.com/2021/06/17/us/earthtrapped-heat-doubled/index.html

18. Saros JE, Stone JR, Pederson GT, Slemmons KE, Spanbauer T, Schliep A, Cahl D, Williamson CE, Engstrom DR. Climate-induced changes in lake ecosystem structure inferred from coupled neo-and paleoecological approaches. Ecology. 2012 Oct;93(10):2155-64.

19. Savin SM. The history of the Earth's surface temperature during the past 100 million years. Annual review of earth and planetary sciences. 1977 May;5(1):319-55.

20. Schmidtko S, Stramma L, Visbeck M. Decline in global oceanic oxygen content during the past five decades. Nature. 2017 Feb;542(7641):335-9.

21. Schneider P, Hook SJ. Space observations of inland water bodies show rapid surface warming since 1985. Geophysical Research Letters. 2010 Nov 1;37(22).

22. Woolway RI, Sharma S, Weyhenmeyer GA, Debolskiy A, Golub M, Mercado-Bettín D, Perroud M, Stepanenko V, Tan Z, Grant L, Ladwig R. Phenological shifts in lake stratification under climate change. Nature communications. 2021 Apr 19;12(1):1-1. 